nature of their work, are not eligible for Nobel Prizes. The MacRobert Award, worth $£ 25,000$ and a gold medal every year, is to be presented to an individual, or a small team of up to five people, who has "made an outstanding contribution, by way of innovation, in the fields of engineering or other physical technologies or in the application of physical sciences, which has enhanced, or will enhance, the national prestige and prosperity of Great Britain".

The MacRobert Trusts were formed by Lady MacRobert-one of the first women to be admitted to fellowship of the London Geological Society and the wife of Sir Alexander MacRobert, the founder of the British India Corporation. The trusts give donations to a wide range of charities and contribute to new enterprises, particularly in Scotland. Some recent donations have been made for the welfare of the services, agricultural research, education and medical research.

The trustees, wishing to use the funds in a charitable way to enhance the economic wellbeing of Great Britain and considering that a major award in the fields of enginecring and the technologies is long overdue, called on the Council of Engineering Institutions (CEI) to administer the MacRobert Award Scheme, and the first prize is to be made in 1969 .

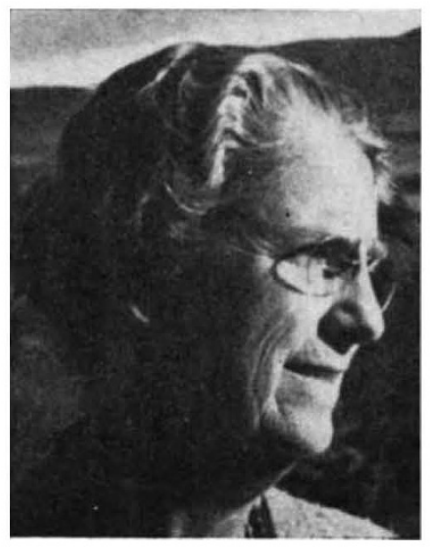

Lady MacRobert of Douneside and Cromar.

The prizewinners will be selected by the CEI, who will be advised by a committee consisting of a chairman and nine members. Lord Hinton, a past chairman of the Central Electricity Generating Board, is to be the first chairman of the selection committee and the other members are nominated by the Royal Society, the CEI and the MacRobert Trusts. If two innovations considered for the award are of equally outstanding merit, the award for that year may be divided but it cannot be split into more than two equal parts. The CEI can decide not to make an award. If the award is given to a team working for an organization, the money will be divided between not more than five employees nominated by the organization. The division of the $£ 25,000$ will be decided by the CEI in consultation with the organization. When the award is made to an individual team, the decisions of the CEI are final. Each member of the team will be given a replica of the gold medal.

The CEI is already receiving applications for the first award. It will be interesting to see whether the CEI can win the prestige of the Nobel Committees.
SPACE

\section{Flight of Fancy}

UNDETERRED or perhaps spurred on by the British Government's determination to withdraw from ELDO, the Conservative Party Political Centre published last week a pamphlet which urges Britain to develop an independent facility for launching synchronous communications satellites. The document, written by $\mathrm{Mr}$ Neil Marten, MP for Banbury, and with an approving introduction by $\mathrm{Mr}$ David Price, MP, says that a launcher could be built by mounting Black Arrow on top of Blue Streak, fitting ion engines to it and hoping that micro-miniaturization will make the satellite small enough to get it up to 22,000 miles. This, it could be said, is to pile conjecture on conjecture, but Mr Marten's pamphlet is no dull technical treatise. On the contrary, it makes the best of its political opportunities. For one thing, it asks the reader to believe that when the Conservative Government invented ELDO in 1960, it did so "perceiving the future benefits of space" rather than simply as a way of minimizing the embarrassment of cancelling Blue Streak. Black Arrow, another Conservative rocket, has been "deliberately slowed down" by the Labour Government.

Whatever the truth, Mr Marten believes that his plan is feasible and that it would be profitable. But it is hard to judge whether his estimates are reliable, for he makes no attempt to assess what the cost of his launcher would be. It is, in fact, rather doubtful whether a British initiative would do anything to accelerate the rate at which the advantages of communications satellites are being seized. Very oftenas in the World Weather Watch-international cooperation is a prerequisite in any case. It would, no doubt, be agreeable for Britain to call the tune, but it is doubtful whether it would be worth the very large investment involved.

\section{URANIUM ORE Slow Strike in Scotland}

GUARDED optimism seems to be the prevailing mood at the United Kingdom Atomic Energy Authority now that the results of the first year of a five year reconnaissance survey of indigenous uranium resources are coming in. Two areas in the north of Scotland have sufficiently high levels of radioactivity to justify further detailed surface surveys and possibly borings. But it remains unlikely that there will ever be a uranium bonanza in Britain. Even allowing for increasing nuclear electricity generation, there are at present no signs of an immediate world shortage of uranium. The latest estimates of world supply, by the European Nuclear Energy Agency and the International Atomic Energy Agency in October 1967, were 826,000 short tons of $\mathrm{U}_{3} \mathrm{O}_{8}$ recoverable for less than $\$ 10$ per pound, 780,000 tons recoverable for $\$ 10-15$ per pound and 664,000 tons for $\$ 15-30$ per pound. On the other hand, predicting the world market has already proved unusually difficult and a few useful deposits may be found in Britain which could by the late seventies be worth exploiting commercially.

That, at least, is the hope. Both the AEA and the Institute of Geological Sciences - which has been hired to make the survey-stress, however, that it is only a 
reconnaissance. As $\mathrm{Mr}$ Wedgwood Benn announced in Parliament on March 20, "the objective is to establish whether there is evidence ... to justify a subsequent more detailed investigation". The programme, which will cost $£ 250,000$ in all, is to survey areas selected by the institute as likely, on geochemical grounds, to contain uranium. This summer the survey teams were in the north of Scotland and the Midlands recording levels of radioactivity along roads and tracks by means of sodium iodide scintillation counters mounted on trucks, surveying rivers and streams on foot and collecting 1,500 water samples for neutron activation analysis. Although many of the data have still to be analysed, the first indications are apparently more or less as predicted. Until borings have been made, there is no knowing the concentration of uranium in the two areas in Scotland with appreciable levels of radioactivity, and the institute is unwilling to disclose the little it knows of the ore bearing rocks because that might reveal the sites and cause problems of one sort or another with landowners and others. As well as making a more thorough surface survey of these two sites in Scotland, the survey teams plan to look at the next two areas on the list next summer, the southern Scottish Uplands and South-West England.

Uranium ore was in fact mined in Cornwall at St Stephen at the turn of this century. Several tons of uranium, which occurs there together with lead ores in high grade veins, were sold to German glass makers who used it as a pigment for stained glass, and the same mine supplied some of the uranium ore used by the Curies as a source of radium, but by 1930 the mine was flooding and has never been worked since. All this, of course, was before the 1946 Atomic Energy Act; if the current surveys reveal commercially worthwhile amounts of uranium there will be the legal nicety of deciding who owns the mineral rights, the Government under the 1946 Act, or the owner of the traditional mineral rights.

\section{MANPOWER}

\section{Labour at the MRC}

IN a recent leading article on the Medical Research Council ("Medical Research Continued", Nature, 219, $426 ; 1968$ ) it was stated that "One particularly disconcerting feature of the council's policy of direct labour is the way in which it may often leave middle-aged professionals high and dry without a job. One way and another, a great many people seem to be embarking on five year appointments with the council which run out at a time when it is usually too late for most people to begin an entirely new career". The MRC has now analysed its personnel records covering the five years 1963-68 and has submitted the following information. Limited appointments give job security for either three or five years. Unlimited appointments mean tenure.

Table 1. PROPORTION OF STAFF WITH LIMITED AND UNLIMITED APPOINTMENTS

$\begin{array}{cccc}\text { Age } & \text { Limited } & \text { Unlimited } & \begin{array}{c}\text { Per cent } \\ \text { unlinited }\end{array} \\ \text { Over } 30 & 365 & 312 & 46 \\ 35 & 156 & 304 & 66 \\ 40 & 47 & 257 & 84 \cdot 5 \\ 45 & 15 & 174 & 92 \\ 50 & 3 & 106 & 97 \\ 55 & - & 55 & 100\end{array}$

Fifty-one per cent of the staff, with at least three months service, in units that have been disbanded or reconstituted in the last five years stayed in the council's service. Of these, 15 people had unlimited appointments and 35 had limited appointments. The other 49 per cent, eight with unlimited and 40 with limited appointments, found other jobs chiefly in the universities and research foundations. Only two people were left with no job to go to immediately; both were in the 31-35 age group and held limited appointments.

Out of a total of 563 people who have left the council's service during the five years, 490 had limited and 73 unlimited appointments. Ten staff with limited appointments had no immediate employment to go to when they left the council's service; nine were over 30 , four were over 35 and three were between 40 and 45 . Ten other people may have been obliged to take unsuitable jobs-this category includes short term jobs, jobs in industry or abroad or jobs at a lower level of responsibility. All ten had limited MRC appointments, all were over 35 , three were over 40 and one over 45 .

\section{BARRAGE BUILDING \\ Damming Morecambe Bay}

THE possibility of a barrage across Morecambe Bay has moved one step forward with the announcement by the Water Resources Board that there appear to be no insuperable engineering difficulties, but this is not to say that plans for the barrage are cut and dried. Although a feasibility study of the proposal to use the bay as a reservoir has been in progress since February 1967 , the full study will not be completed until the end of 1970 or even 1971, and only then will the Government be able to decide whether to go ahead with the scheme. Many will think it premature, therefore, to side either for or against the barrage, which is why some of the official bodies in the area are keeping quiet. There is, however, a growing number of objectorslocal fishermen, trades people, representatives of amenity bodies and so on. Some of these hope that the feasibility study will come out against Morecambe Bay as the site for a barrage and that attention will be switched instead to the Solway Firth, on which there has already been a desk study and which is thought to be a much more practical and acceptable scheme.

Meanwhile, to allay the fears of local people, committed objectors or not, the Water Resources Board recently organized a meeting in Morecambe and at the same time issued a statement on the progress of the $£ 500,000$ feasibility study.

Some studies have already been completed. These include aerial and hydrographic surveys and contour maps of the bay. The subsurface investigations have involved a survey over about 22 miles on possible lines of embankment dams and the sinking and re-sealing of some 29 boreholes. At the Hydraulics Research Station at Wallingford, a large-scale model of the bay has been constructed, and surveys have been completed of current flows and the nature of the bed of the bay. Other studies in progress involve the Natural Environment Research Council, the Nature Conservancy and the Lancashire River Authority. Much remains to be done, including testing of the various possibilities on the hydraulic model. 